\title{
VIEWS ON THE NINE PRINCIPLES OF ARCHAEOLOGICAL ETHICS FROM THE 2020 SAA ETHICS SURVEY
}

\author{
Kaylee Pruski, Ben Marwick, Eloise Potter, Raelee Hampton, and Li-Ying Wang

\begin{abstract}
Kaylee Pruski is an undergraduate student in the Department of Anthropology at the University of Washington. Ben Marwick is an associate professor in the Department of Anthropology at the University of Washington. Eloise Potter is a graduate of the Department of Anthropology at the University of Washington. Raelee Hampton is an undergraduate student in the Department of Anthropology at the University of Washington. Li-Ying Wang is a graduate student in the Department of Anthropology at the University of Washington.
\end{abstract}

$\mathrm{n}$ the spring of 20I8, the Society for American Archaeology (SAA) initiated the process of updating and revising the SAA Principles of Archaeological Ethics. As part of this process, the SAA created the Task Force on Revising the SAA Principles of Archaeological Ethics: Stage Two (TF-2), which would collect, organize, and analyze results from a survey (see Rakita and Gordon, this issue, for more details about the work of TF-2). This survey was available online between April and June of 2020 and was open to SAA members and nonmembers. Consisting of 3I questions, the survey received responses from I,542 people (including I,II2 SAA members). A key objective was to gauge reactions and attitudes of respondents toward the current SAA Principles of Archaeological Ethics. This article reports the survey results relevant to those principles, which can be found at https://www.saa. org/career-practice/ethics-in-professional-archaeology and which are reprinted in this issue of the Record. We first summarize the respondents' demographics, and how they are using the principles. We then summarize reactions to each of the nine principles and responses to questions about how the principles address situations and concerns. These data provide an indication of the overall level of satisfaction with the current SAA Principles of Archaeological Ethics. Finally, we conclude with some guidance for considering future revisions of the principles.

In addition to this article, there is also a detailed description of our qualitative data analysis methods and statistical methods in our online supplementary materials (http:// doi.org/I0.I7605/OSF.IO/643C8). These materials include a compendium of $\mathrm{R}$ code used to produce the figures presented here (e.g., Marwick et al. 20I8), the full text of the survey responses (excluding personal data), and the full report submitted to the SAA Board of Directors.

\section{Demographics of Respondents}

Multiple correspondence analysis of demographic variables demonstrated that there is limited demographic diversity among the respondents to this survey (Figure I), with most respondents clustered in the age groups of 40 years and older and Caucasian (non-Hispanic) ethnicity. We speculate that younger members of the Society may be underrepresented in the responses. This is a problem because younger members are also in our data more often associated with the LGBTQIA+ community and nonbinary gender identity than are older members, so small numbers of younger respondents also mean limited LGBTQIA+ and nonbinary respondents. In light of the high frequency of Indigenous themes throughout responses to questions in this survey, Native Americans, who made up only I\% of respondents, are another important demographic category that is underrepresented.

As a baseline for establishing the representativeness of this survey about the principles, we can compare demographic variables to values obtained from the SAA 2020 Member Needs Assessment (MNA; https://ecommerce. saa.org/SAA/SAAdocs/Survey2020/ExecutiveSummary. pdf, 839 responses). Note that the MNA excluded nonresponses before computing percentages, unlike this survey. This means that ordinal comparison is more meaningful than the direct comparison of percentage values. Ethnic representation is similar for the two surveys with the MNA reporting "White or Caucasian" (83.5\%) and "Latino or Hispanic" (5.8\%) as the top two groups, compared to "Caucasian (non-Hispanic)" (51\%), followed by "Hispanic/Latino(a)" (3\%) for this survey. Current place of residence was dominated by the United States 


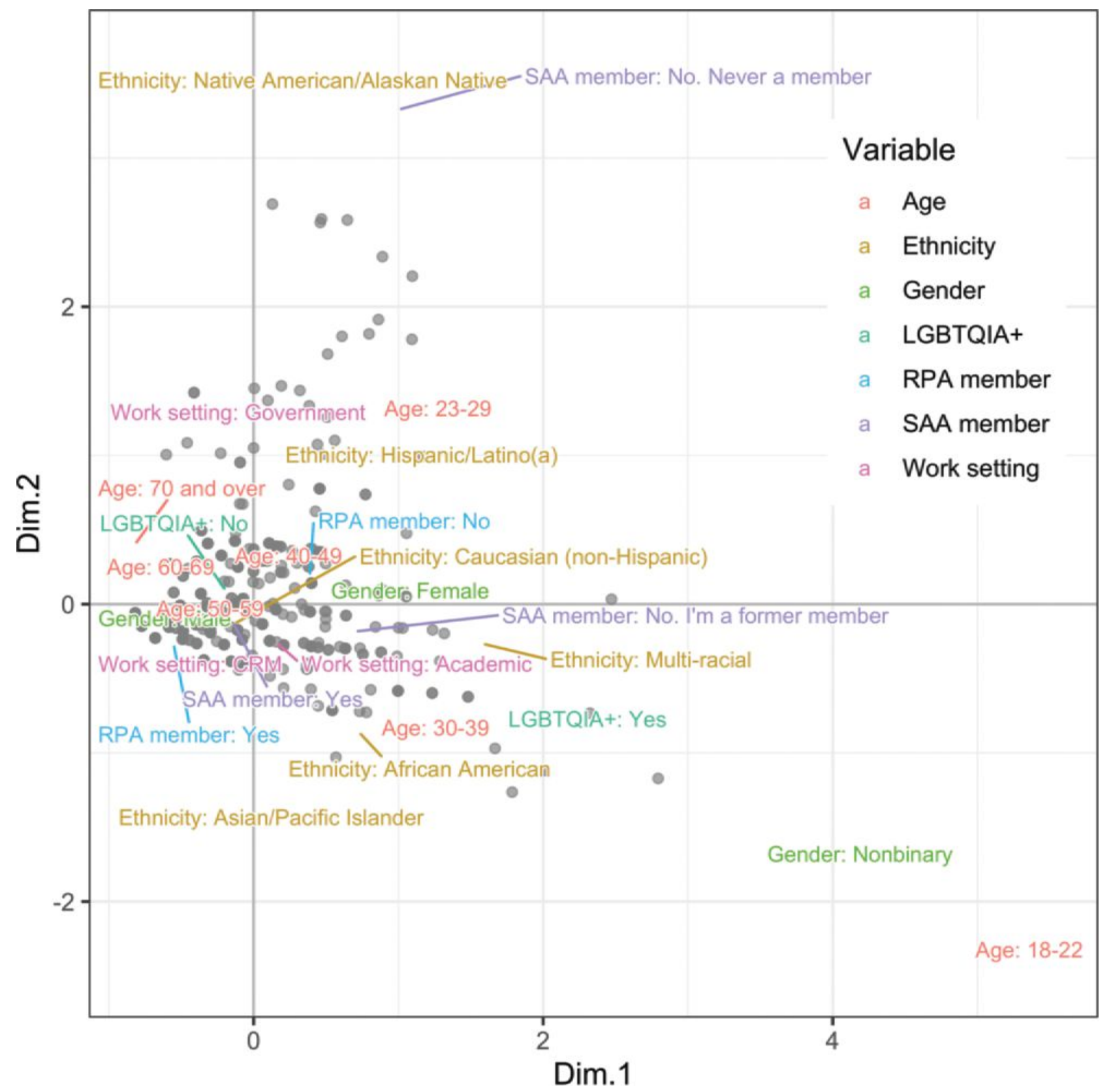

Figure 1. Multiple correspondence analysis summarizing demographic diversity among survey respondents (each data point is one respondent). The horizontal axis mostly captures variation in the age and gender of the respondents, with younger, non-male respondents appearing on the right. The vertical axis mostly represents the ethnicity variable, with most respondents identifying as Caucasian (non-Hispanic). 


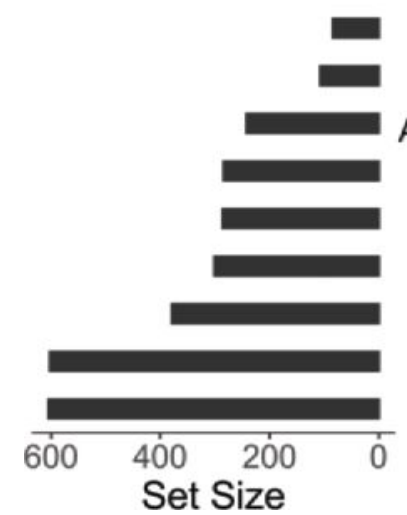

Other

Referred to it while renewing my SAA membership As a student in an archaeological class or field school To write a report, article, or publication To address an ethical problem I have not used the Principles In working with the public or non-archaeologists For teaching or training purposes To refresh or gain personal knowledge of ethics

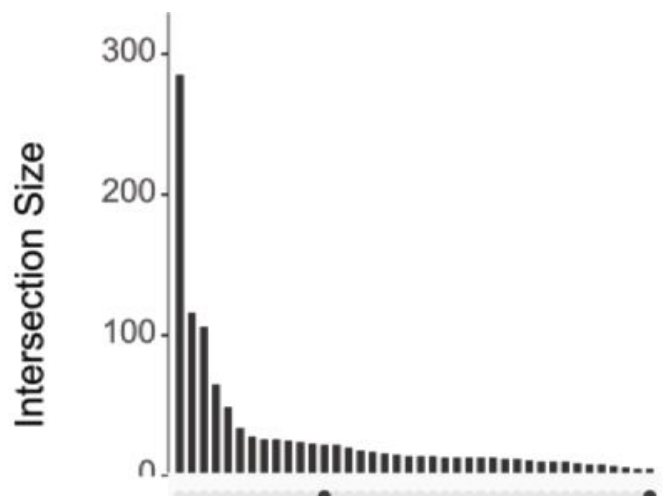

Figure 2. UpSet plot of the respondents to the multiple-choice question about how respondents have used the principles.

and Central/South America in both surveys (MNA: 89\%, 2\%; this survey: $61 \%, 2 \%)$. Representation of work settings is also similar, reporting the top three categories as academics $(43 \%)$, CRM (I3\%), and government (I4\%) in the MNA, compared to this survey with academics (28\%), CRM (II\%), and government (9\%). The age of respondents is skewed to people over 40 in both the MNA (62\%) and this survey $(47 \%)$. The wording of questions about the sexual identities of respondents differed between the MNA and this survey. In the MNA, 84\% identify as heterosexual, and $6_{3} \%$ in this survey identify as male or female (who may also identify as homosexual). In the MNA, $9 \%$ identify as homosexual/pansexual/bisexual/asexual, and $6 \%$ in this survey identify with the LGBTQIA+ community. Overall, the demographic profile of respondents to the 2020 SAA Ethics Survey is similar to the 2020 MNA. However, because both surveys represent a relatively small fraction of the roughly 7,000 members of the SAA, we cannot be sure this is capturing SAA demographics accurately.

\section{Use of the Principles}

About a third of respondents stated that they had never used the SAA Principles of Archaeological Ethics (Figure 2).

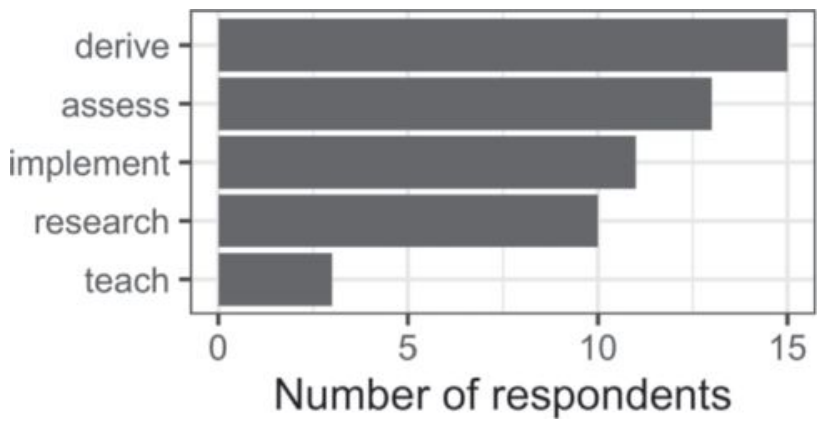

Figure 3. Themes in the free text responses to the question about how the principles are used. For definitions of the themes, see our online supplementary materials (http://doi.org/10.17605/OSF.IO/643C8).

The most commonly selected purpose for consulting the principles was "To refresh or gain personal knowledge of ethics" or both "To refresh or gain personal knowledge of ethics" and "For teaching or training purposes" (Figure 3).

Our qualitative data analysis identified four key themes in the 77 free text responses, with the theme of "Derivation" being the most prominent. Many respondents stated they consulted the principles to draft similar documents for 


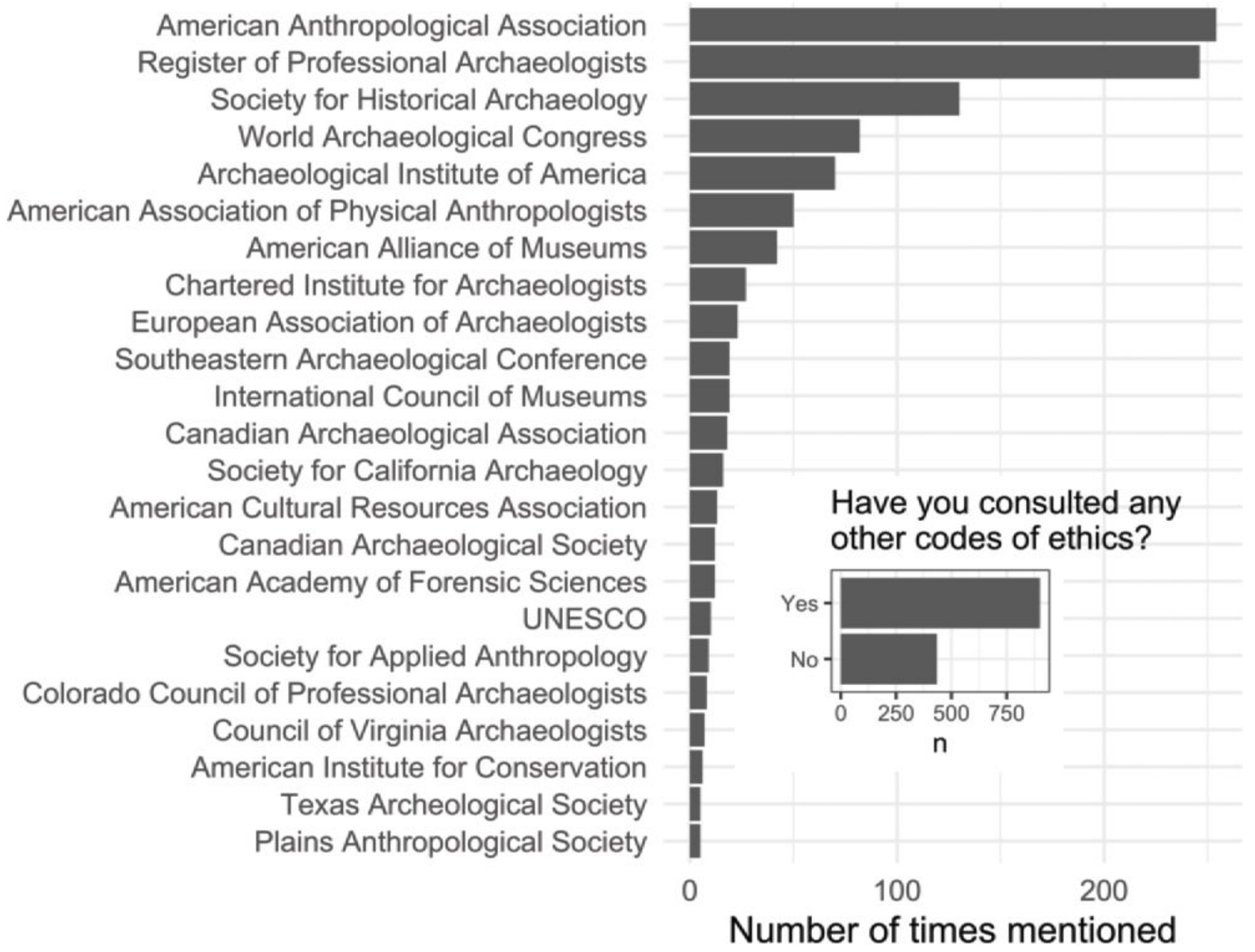

Figure 4. Other organizations mentioned by respondents. Only those mentioned by more than five respondents shown here. A total of 121 organizations were mentioned by 1,542 respondents.

other organizations or events (Figure 3). We also noted an evaluative use of the principles, with some respondents finding a gap between their expectations about how the principles should have guided the SAA leadership, and the leadership's actions in response to the events of the 2019 SAA Annual Meeting (Wade 20I9).

Respondents who mentioned consulting other documents were most frequently using the principles together with the equivalent documents of the American Anthropological Association (AAA) and the Register of Professional Archaeologists (RPA) (Figure 4). The AAA provides extensive supporting documentation for its code of ethics, or "Principles of Professional Responsibility" (ca. 4,600 words, compared to the SAA principles at ca. 870 words). The RPA differs from the SAA and AAA with its formal grievance procedure that allows for the investigation of complaints regarding the professional conduct of a member who has violated the RPA's Code of Conduct of Standards and Research Performance (ca. I,700 words). Another II9 organizations were referenced by respondents. These include state and regional archaeological societies and associations and associations of other scientific communities.

\section{The Nine Principles}

The survey included one question for each of the nine current principles, with the prompt "I feel that this principle and its description adequately applies to archaeological 


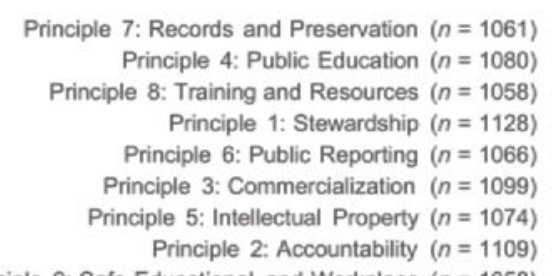

Principle 9: Safe Educational and Workplace $(n=1058)$

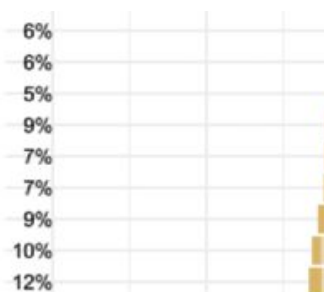

100

50 b
Principle 7: Records and Preservation $(n=243) \quad 20 \%$ Principle 4: Public Education $(n=251) \quad 23 \%$ Principle 1: Stewardship $(n=311) \quad 26 \%$ Principle 6: Public Reporting ( $n=301) \quad 23 \%$ Principle 8: Training and Resources $(n=229) \quad 20 \%$ Principle 5: Intellectual Property $(n=331) \quad 24 \%$ Principle 3: Commercialization $(n=281) \quad 22 \%$ Principle 2: Accountability $(n=341) \quad 28 \%$ Principle 9: Safe Educational and Workplace $(n=329) \quad 32 \%$

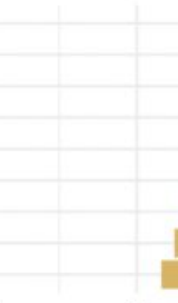

50

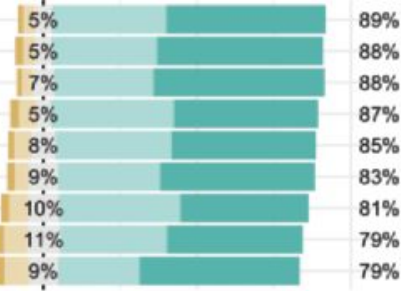

50 100
Response

Strongly Disagree Disagree Neutral Agree Strongly Agree

Figure 5. Summary of the Likert-type responses to the prompt "I feel that this principle and its description adequately applies to archaeological practice and its ethical challenges today" for each of the nine principles: (a) all survey respondents; (b) only the subset of respondents that also submitted a text response on the principle.

practice and its ethical challenges today." The majority of respondents $(79 \%-89 \%)$ agreed or strongly agreed with this statement for all nine principles (Figure 5). Disagreement was highest for Principle No. 9 (ז2\% strongly disagree or disagree, Safe Educational and Workplace Environments), Principle No. 2 (io.4\%, Accountability), and Principle No. 5 (8.7\%, Intellectual Property [IP]). Respondents who also submitted a text response about the principles agreed less frequently $(48 \%-70 \%)$ that the principles were adequate (Figure 5). Key themes that were ubiquitous in the free text responses to all the questions about the nine current principles were Indigenous people, sexual harassment, and open science. To assist the SAA in identifying opportunities to improve its documentation on ethics, we focus here on those three principles where disagreement was highest.

Responses to Principle No. 2 (Accountability) varied significantly by ethnicity, with African Americans and Native Americans disagreeing more than other ethnic groups that the "Principle and its description adequately applies to archaeological practice and its ethical challenges today" (Figure 6). Among the 34I free text responses, recurrent themes identified by qualitative data analysis were enforcement, Indigenous people, and conflicts of interest. A common sentiment in the free text responses was that the principle was too vague and that Indigenous, descendant, and local communities should be in a special category of "affected groups" where collaboration is mandatory before and during fieldwork.

Qualitative data analysis of the 33I free text responses to Principle No. 5 (IP) found that the most frequently mentioned theme was open science, a result also independently supported by our semantic network of high-frequency word co-occurrence (Figure 7). This theme often co-occurs with mention of Indigenous people, IP and copyright, and expression of concern about how to enforce sharing data. Many respondents expressed concern that data availability and sharing standards in archaeology were not up to date with other fields, and that Indigenous groups were not properly involved in decision making about archaeological data. There were no significant differences in responses to this question by any demographic category.

The 329 free text responses to Principle No. 9 (Safe Educational and Workplace Environments) varied significantly by the age of respondents (Figure 8). Generally, agreement with "This principle and its description adequately applies to archaeological practice and its ethical challenges today" increased with the age of the respondents. Former members of the SAA disagreed significantly more than SAA members, suggesting that issues surrounding this principle may negatively affect membership retention. Qualitative data analysis found that the theme of 

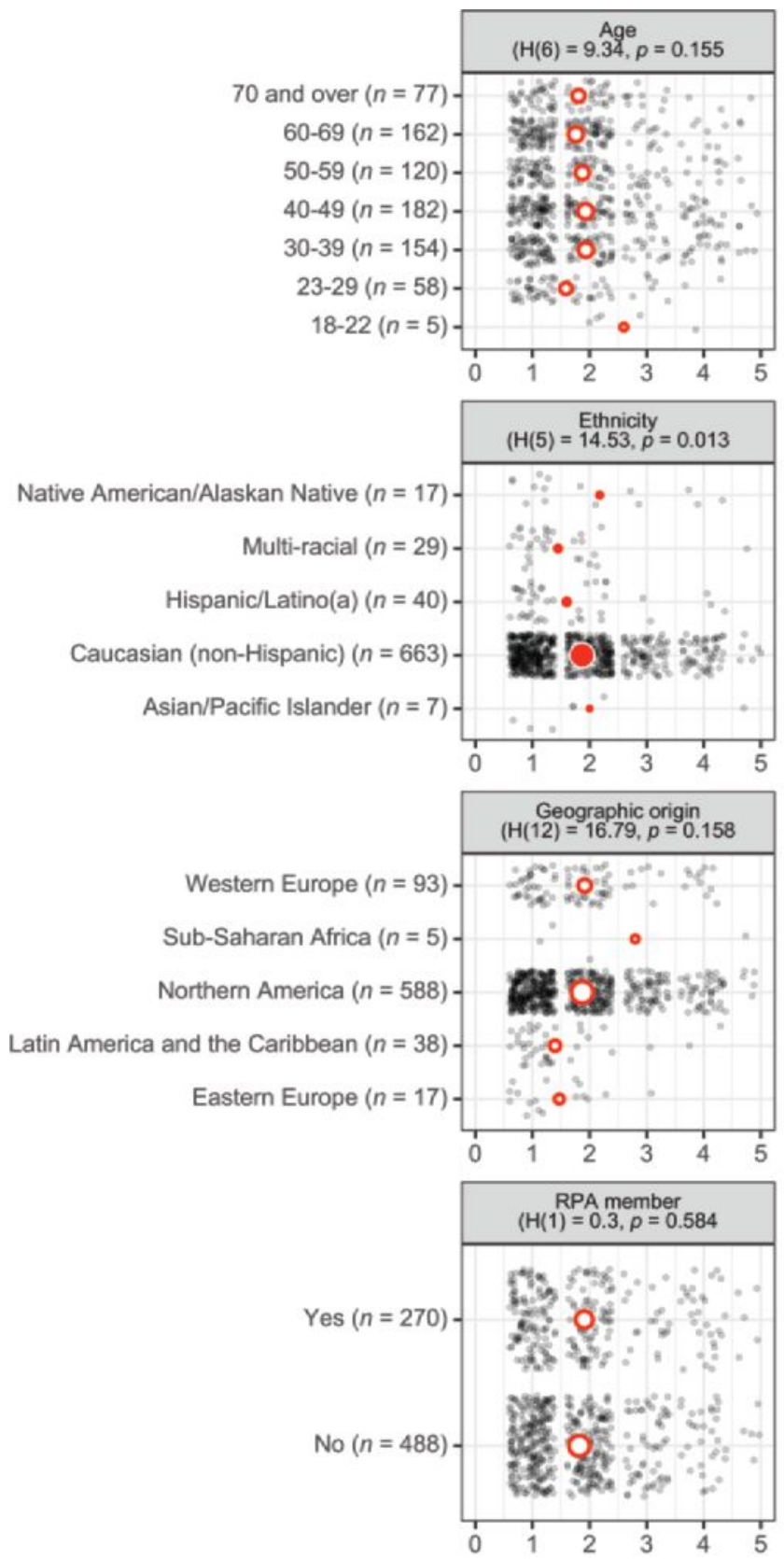
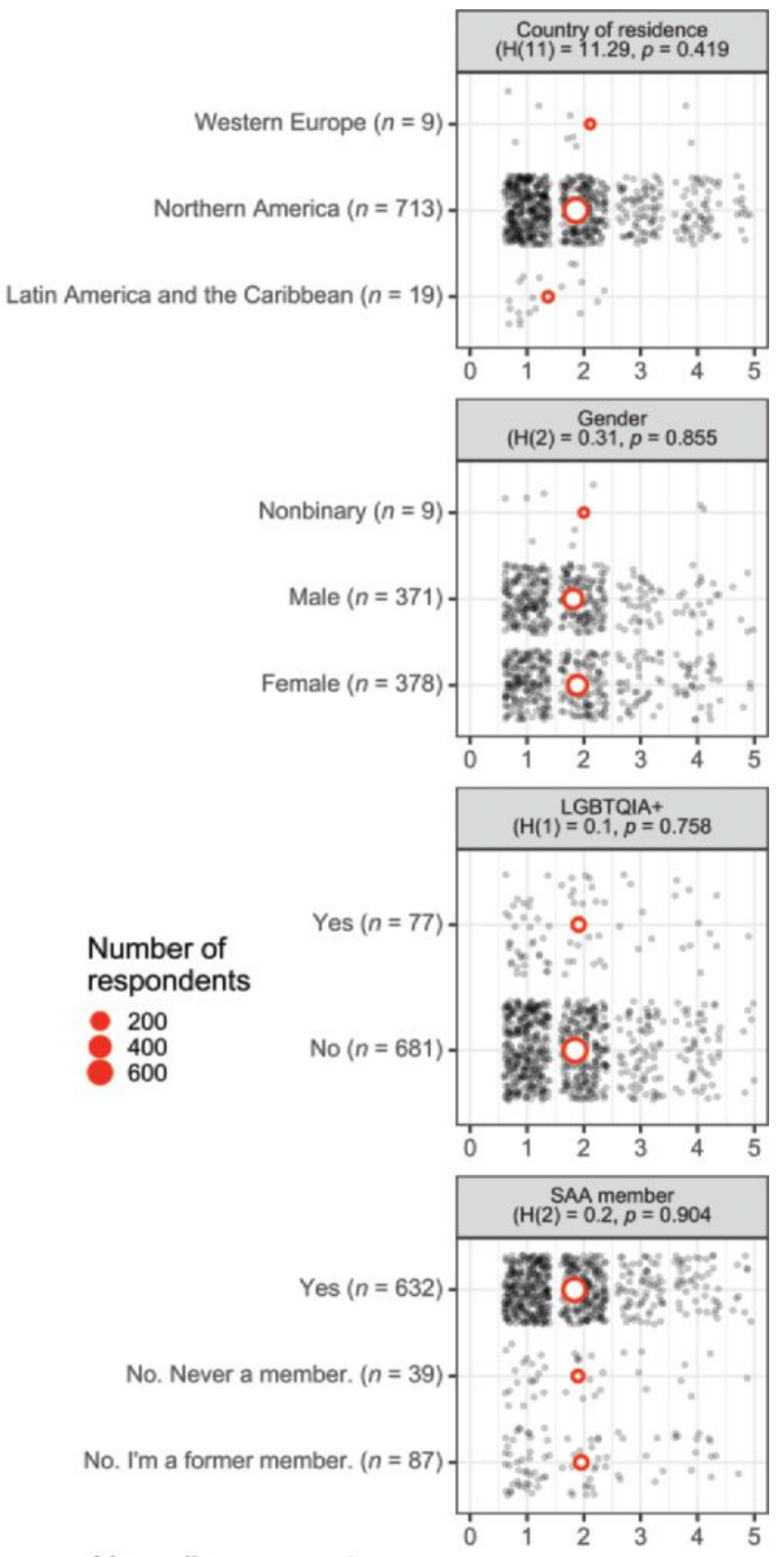

\section{Mean disagreement}

Figure 6. Plots of mean disagreement (5 = Strongly Disagree) by demographic category for the Likert-scale responses about Principle No. 2 (Accountability). Each gray data point is a single respondent; red circles indicate mean values. Solid red circles indicate significant differences between categories. Only categories with five or more respondents are shown here. 
sexual harassment, and concerns about how archaeologists can be protected, was prevalent throughout the 329 free text responses for Principle No. 9. The free text responses indicate a perception of the SAA as ineffective at maintaining safe environments, with frequent reference to the 2019 annual meeting. Concern was also expressed in the free text responses about how to ensure safety in field locations where U.S. law does not apply.

We analyzed correlations among the Likert responses (strongly agree, agree, etc.) to all of the questions about the nine principles to investigate latent factors that might underlie how people think about archaeological ethics (Figure 9). We found two broad groups among the respondents: (I) those that value relationships intrinsic to archaeology-for example, between archaeologists, and between archaeologists and the archaeological record; and (2) those that value extrinsic relationships-for example, between archaeologists and the public, Indigenous and descendant communities, and other groups that are not mostly composed of archaeologists (Figure 9).

These latent factors map on to the dominant themes in the free text responses to the nine principles. For example, the intrinsic relationships latent factor corresponds to concerns about sexual harassment and data sharing, while the extrinsic relationships factor relates to archaeologists' duties to Indigenous, descendant, and local communities. These latent factors help us to see what are the most urgent and substantial concerns for the respondents to the survey, and may be useful to guide the SAA on where to focus its attention on future activities relating to ethics.

\section{How the Current Principles of Ethics Address Situations and Concerns}

The survey included three questions about how the principles address situations and concerns: "As a whole, the SAA Principles of Ethics satisfactorily addresses the ethical situations archaeologists find themselves in today," "The SAA Principles of Ethics adequately addresses ethical concerns in the country in which I work, am a student, or teach," and "The SAA Principles of Ethics adequately addresses ethical concerns in the sector in which I work." For these three survey questions, we see higher levels of dissatisfaction (16\%-I9\%; Figure го) compared to the individual principles $(5 \%-\mathrm{I} 2 \%)$. Disagreement was significantly higher among respondents who are in the 30-39-year-old age category, who are women or nonbinary gender individuals, and who identify with the LGBTQIA+ community. Generally, members of minority demographic groups in the SAA are less satisfied with how the current principles address their situations and concerns.

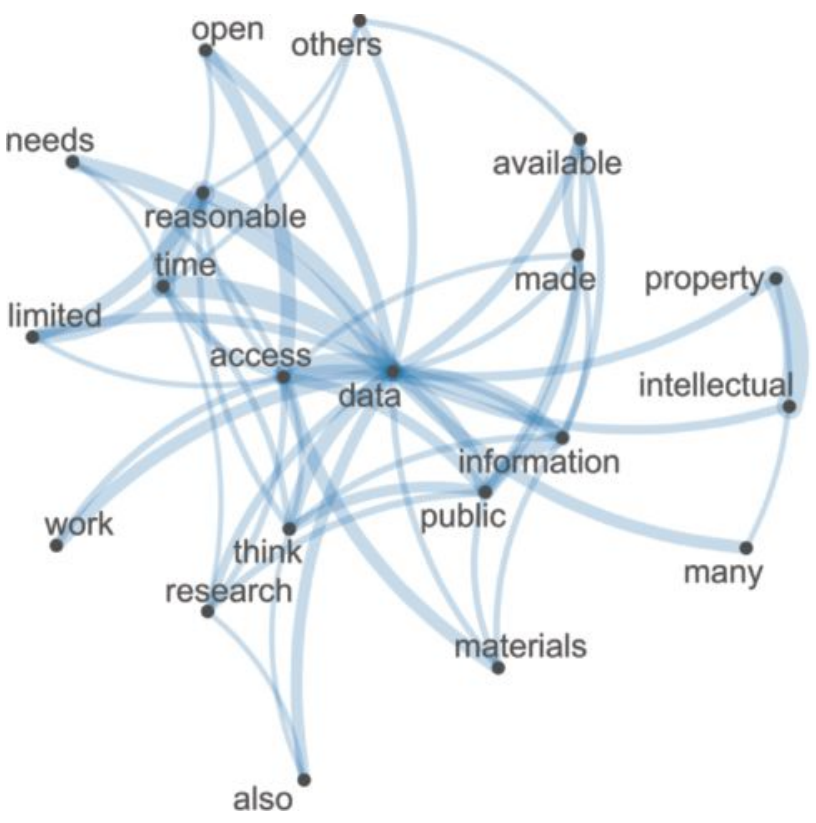

Figure 7. Semantic network of high-frequency word co-occurrence in the 331 free text responses about Principle No. 5.

The higher proportions of disagreement for these "situations and concerns" questions compared to the questions about the individual nine principles are noteworthy. It suggests a distinction between responses to the individual principles as mostly responses to the concepts or aspiration of the principles. On the other hand, responses to these three "situations and concerns" questions are more about the application and practical use of the principles. While many respondents generally approve of the principles (see Figure 5), there is less satisfaction among respondents with how effective the principles are at addressing situations and concerns (Figure IO). This contrast highlights the need for interpretive and supporting documentation that discusses specific examples and more concrete standards of practice for typical situations and concerns (e.g., Thulman and Booth 2020).

"Indigenous communities" was the most common theme throughout the free text responses to the three "situations and concerns" questions. Respondents advocated for a greater role of Indigenous communities in the archaeological process. There were a small number of contrary responses that expressed concern that higher levels of Indigenous community involvement in archaeology might have negative effects. This concern has been noted in previous discussions of archaeological ethics. For example, Wylie (I999:329) noted 

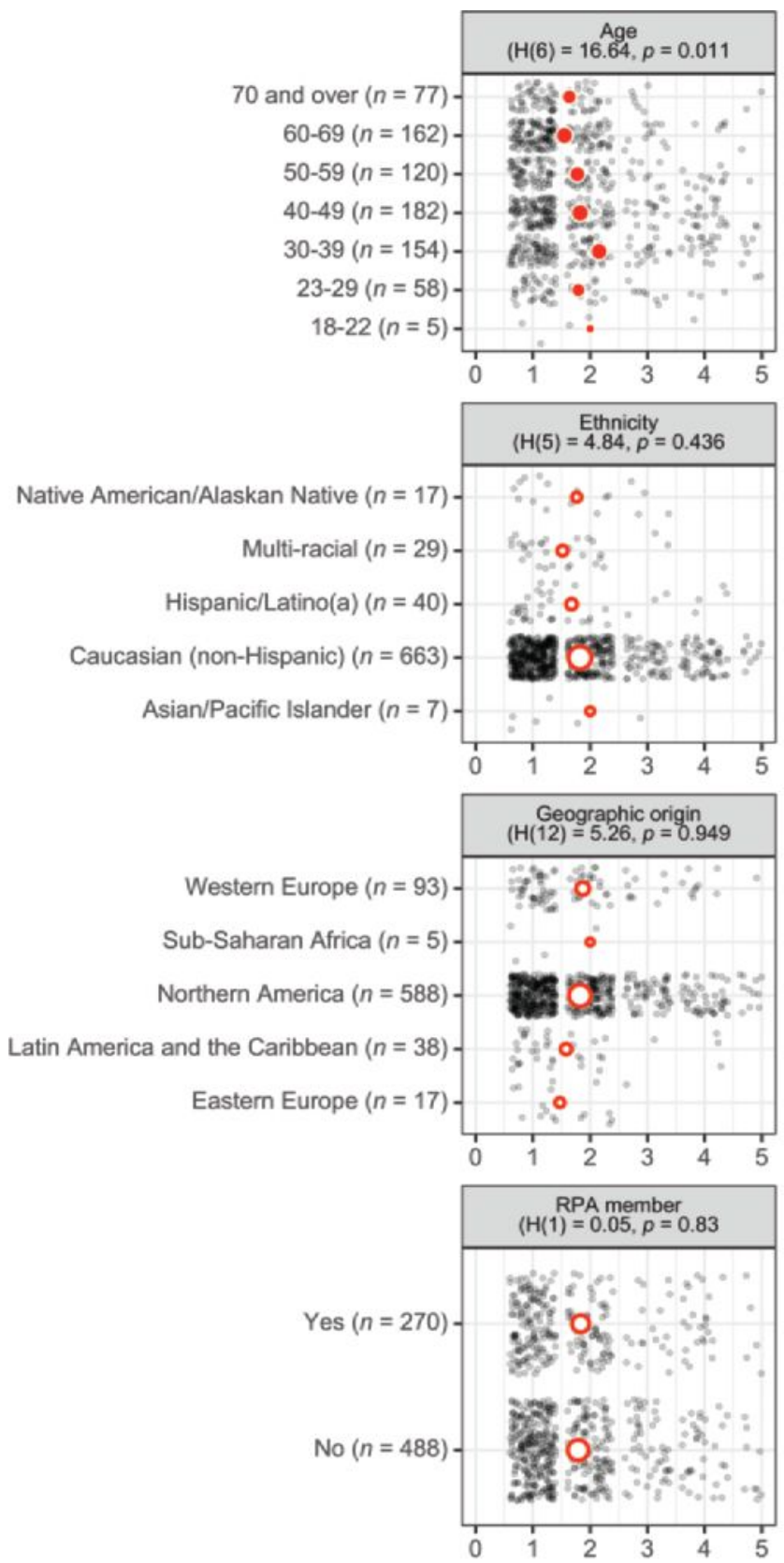
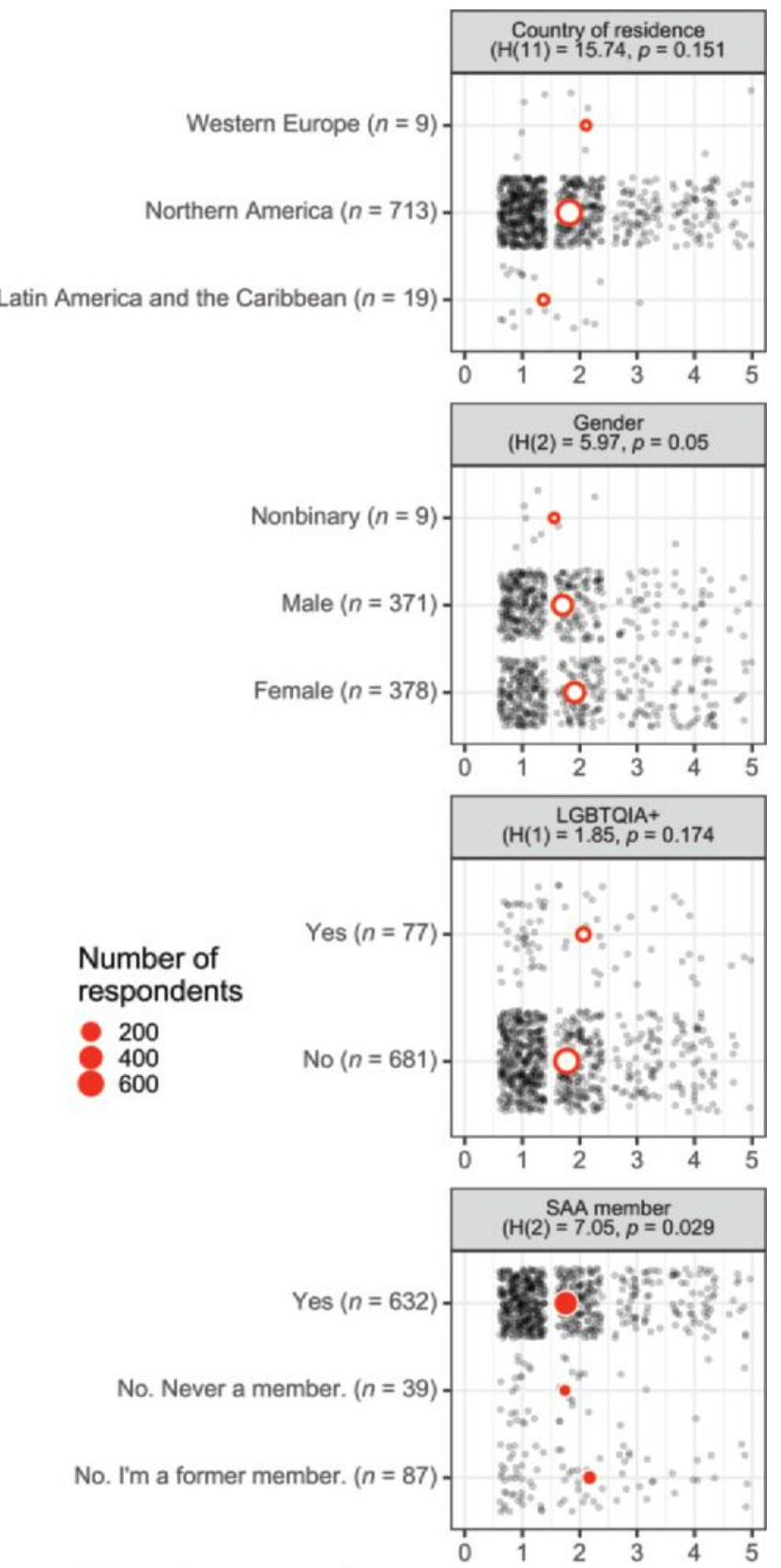

\section{Mean disagreement}

Figure 8. Plots of mean disagreement ( 5 = Strongly Disagree) by demographic category for the Likert-scale responses about Principle No. 9 (Safe Educational and Workplace Environments). Each gray data point is a single respondent; red circles indicate mean values. Only categories with five or more respondents are shown here. Solid red circles indicate significant differences between categories. 
a

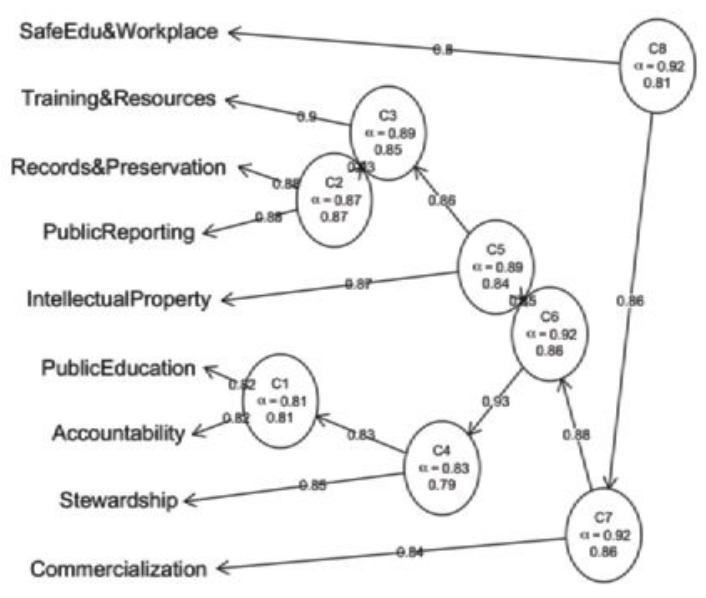

b

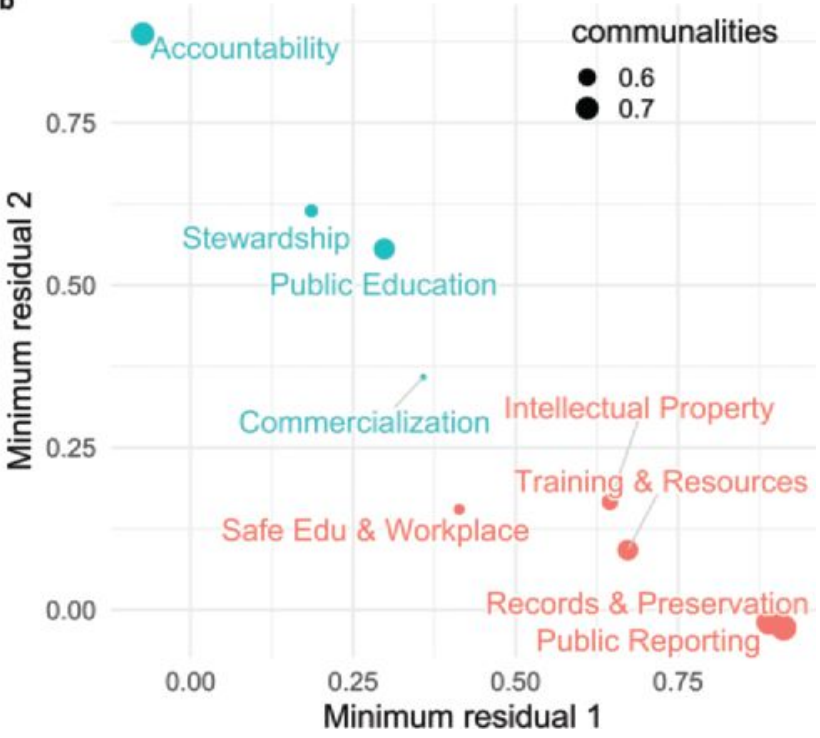

Figure 9. (a) Dendrogram showing Item Cluster Analysis (ICLUST) results of Likert-type responses to the nine principles. Variables that cluster together have more correlated responses and indicate similar degrees of practical importance to respondents. (b) Results of latent variable exploratory factor analysis of the nine principles, grouped into the two dominant latent factors identified by confirmatory factor analysis. Latent factors are meaningful but not observable factors that structure the data. The two groups indicate underlying variables inferred from the survey responses that influence how people responded to the individual principles. Communalities represent the fraction of the variance in the observed variable that is accounted for by the latent factors. For more details about these analyses, see our online supplementary materials (http://doi. org/10.17605/OSF.IO/643C8).

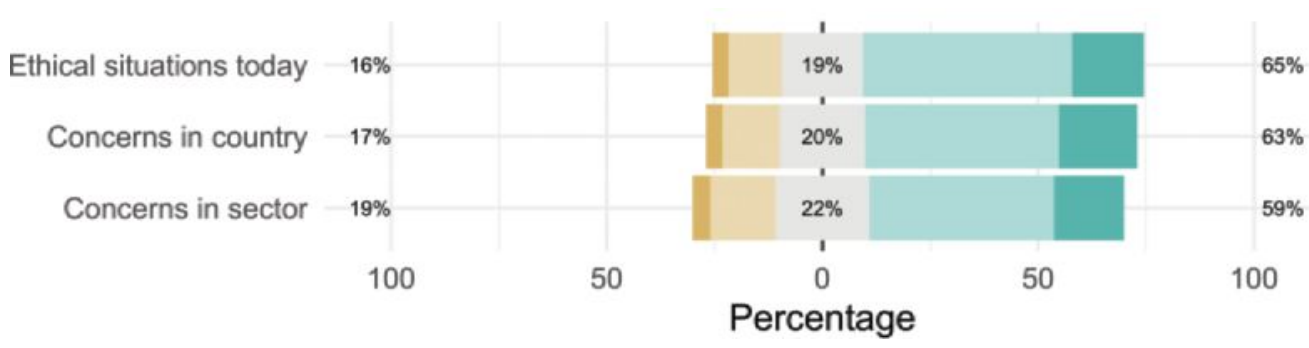

\section{Response}

Strongly Disagree Disagree Neutral Agree Strongly Agree

Figure 10. Summary of the Likert-type responses for statements about whether the principles adequately address situations and concerns that arise in archaeological practice. The full text of the statements is "As a whole, the SAA Principles of Ethics satisfactorily addresses the ethical situations archaeologists find themselves in today," "The SAA Principles of Ethics adequately addresses ethical concerns in the country in which I work, am a student, or teach," and "The SAA Principles of Ethics adequately addresses ethical concerns in the sector in which I work."

that some SAA members have long been hostile to what they consider to be a breach of their "rights and interests as scientists" resulting from the involvement of Indigenous groups.

A second prominent theme in the "situations and concerns" responses was enforcement, especially with respect to local laws and norms. Generally, the theme of enforcement was reflecting concerns about the lack of consequences for archaeologists who do not follow the principles in ways expected by others in the Society. This theme occurs with themes of Indigenous communities and sexual harassment, and a desire for more specific guidance about best practices.

\section{Discussion and Conclusion}

Many of the tensions described by Wylie (2005) that surrounded the initial drafting of the SAA Principles of 
Archaeological Ethics remain evident in the responses to this survey, including who should have access to and control over archaeological sites and materials. This makes it challenging to identify future directions for the text of the principles that will be unanimously supported by the SAA membership.

Nevertheless, our results suggest that most survey respondents would support updates to the text that give a special role in the archaeological process to Indigenous, descendant, and local communities (e.g., Watkins 20I2). For example, Principle No. 2 currently uses the phrase "A commitment to make every reasonable effort, in good faith, to consult actively with affected group(s)," and a minimalist edit might change this to "Must consult actively with Indigenous, descendant, and local communities." Principle No. 5, on intellectual property, could similarly be edited to require consultation with Indigenous, descendant, and local communities to determine who has access to and control over the knowledge and documents resulting from the archaeological process.

A second prominent theme in responses to this survey that could be incorporated into the text of the principles with minimal edits is open science, including data availability and data sharing practices. Principle No. 7 on Records and Preservation was drafted before the appearance of many of the technologies, standards, and repositories for digital data sharing and archiving that are now ubiquitous in many scientific communities. These new technologies have led to the appearance of new norms in many scientific communities. For example, several prominent economics and political science journals require all papers to be accompanied by an archived compendium of digital files of the data and code used to generate the results presented in the paper. Principle No. 7 could be edited to state that, unless it would put people or the archaeological record at risk, archaeologists should deposit their digital data records in nonprofit online repositories for unrestricted access by others and long-term storage.

Sexual harassment and bullying were major themes in the free text responses to this survey. Principle No. 9 on Safe Educational and Workplace Environments currently represents these concerns. Meyers (this issue) discusses the origins of Principle No. 9 in 2016 , and related subsequent SAA actions for addressing sexual harassment. Meyers's review and the results of this survey indicate that there is an unmet need to manage this issue to ensure the future of archaeology as a discipline, especially concerning the inclusion of women and LGBTQIA+ people (Clancy et al. 20I4; Meyers et al. 2015, 2018; Nelson et al. 20I7; Radde 20I8; VanDerwarker et al. 20I8). This accumulation of evidence makes the current wording of the principles appear insufficient for the extent of the problems and damage that have been caused by sexual harassment and assault in archaeology. Principle No. 9 should be edited to directly and concretely state that harassment of any kind is unacceptable to the archaeological community. That said, revisions to this principle will likely not be sufficient to satisfy concerns about sexual harassment. The main issue with this theme was not that it is missing from the principles, but rather that the SAA has had no enforcement mechanism (or has not employed available mechanisms) to satisfactorily manage grievances and to punish or censure violators.

While concerns about racism were not as prevalent as sexual harassment in the survey responses, they often co-occurred in the text responses and were frequently accompanied by related broad structural and systemic issues such as gender and economic inequality, colonialism, and classism. Three respondents noted surprise at the absence of mention of racial harassment and discrimination in Principle No. 9 on Safe Educational and Workplace Environments. The principle currently lists sex, gender identity, sexual orientation, ethnicity, disability, national origin, religion, or marital status. We speculate that "Race" may have been avoided here by the original authors of this principle in favor of "Ethnicity" as a more anthropologically precise term to reference issues that typically intersect with racial discrimination.

However, the recent increase in public and scholarly discussions of racism due to the protests in 2020 about the killing of George Floyd and violence against Black Americans generally have solidified "racism" as the term of reference to long-term systemic discrimination against Black people that has resulted in disproportionally disadvantaged social, economic, educational, and political conditions (e.g., Ike et al. 2020). This shift in public discourse on racism suggests that Principle No. 9 needs some editing to expand the list to include race. This would be a minimal step the SAA can take to show recognition of the extent and negative effects of racism on the archaeological community. After reviewing examples of lists of common types of harassment in numerous other codes of conduct, we propose this updated list for Principle No. 9: age, body size, disability, gender identity and expression, physical appearance, race, religion, relationship status, or sexual orientation. This includes race and other targets of harassment that have emerged in academic and professional communities in recent years.

The information received from this survey has given substantial insight into the attitudes and sentiments of both 
SAA members and other stakeholders on archaeological ethics. Our analysis and interpretations of survey responses demonstrate the need for revision of the SAA Principles of Archaeological Ethics. Revisions are especially necessary to provide archaeologists with updated guidance on interpersonal relationships, Indigenous communities, and open science. Our results also indicate demands for supporting documentation, and for concrete consequences for demonstrated violations of the principles.

\section{Acknowledgments}

Warm thanks to Sarah Miller (TF-2 chair) and colleagues on TF-2: John Douglass, Sarah Herr, Meredith Langlitz, Patricia Markert, Maureen Meyers, Gordon Rakita, Eldon Yellowhorn, and Elizabeth Pruitt. Thanks to the SAA Board of Directors for funding for the student authors of this article to work on the survey data analysis, and for feedback on a draft of the full report. Thanks also to Chris Rodning, editor of the SAA Archaeological Record, for his helpful editorial guidance.

\section{References Cited}

Clancy, Kathryn B. H., Robin G. Nelson, Julienne N. Rutherford, and Katie Hinde

2014 Survey of Academic Field Experiences (SAFE):

Trainees Report Harassment and Assault. PLoS ONE

9(7):eIo2I72. DOI:https://doi.org/10.I37I/journal. pone.0I02I72.

Ike, Nkem, Gabrielle Miller, and Gabby Omoni Hartemann 2020 Anti-Racist Archaeology: Your Time Is Now. SAA Archaeological Record 20(4):I2-16.

Marwick, Ben, Carl Boettiger, and Lincoln Mullen 20I8 Packaging Data Analytical Work Reproducibly Using R (and Friends). American Statistician 72:80-88. DOI:https://doi.org/10.1080/00031305.20I7.I375986.

Meyers, Maureen, Tony Boudreaux, Stephen Carmody, Victoria Dekle, Elizabeth Horton, and Alice Wright

20I5 Preliminary Results of the SEAC Sexual Harassment Survey. Horizon and Tradition 57(I):I9-35.
Meyers, Maureen S., Elizabeth T. Horton, Edmond A. Boudreaux, Stephen B. Carmody, Alice P. Wright, and Victoria G. Dekle

20I8 The Context and Consequences of Sexual Harassment in Southeastern Archaeology. Advances in Archaeological Practice 6:275-287.

Nelson, Robin G., Julienne N. Rutherford, Katie Hinde, and Kathryn B. H. Clancy

20I7 Signaling Safety: Characterizing Fieldwork Experiences and their Implications for Career Trajectories. American Anthropologist II9:710-722.

Radde, Hugh D.

20I8 Sexual Harassment among California Archaeologists: Results of the Gender Equity and Sexual Harassment Survey. California Archaeology 10:23I-255.

Thulman, David K., and Keely J. Booth 2020 Casuistry: A Method for Analyzing Novel Ethical Problems in Archaeology. SAA Archaeological Record 20(5):4I-44.

VanDerwarker, Amber M., Kaitlin M. Brown, Toni Gonzalez, and Hugh Radde

20I8 The UCSB Gender Equity Project: Taking Stock of Mentorship, Equity, and Harassment in California Archaeology Through Qualitative Survey Data. California Archaeology I0:I3I-I58.

Wade, Lizzie

2019 \#MeToo Controversy Erupts at Archaeology Meeting. Science 364:219-220. DOI:https://doi.org/I0.II26/science. aax7037.

Watkins, Joe

2012 "The Principles of Archaeological Ethics as a Living Document: Is Revision Necessary?" A Request from the SAA Committee on Ethics. SAA Archaeological Record I2 (2):27-30.

Wylie, Alison

I999 Science, Conservation, and Stewardship: Evolving Codes of Conduct in Archaeology. Science and Engineering Ethics 5:319-336.

2005 The Promise and Perils of an Ethic of Stewardship. In Embedding Ethics, edited by Lynn Meskell and Peter Pels, pp. 474-468. Berg, Oxford. 